\title{
ENSURING SUCCESS IN THE FLIPPED CLASSROOM WHEN TEACHING ON- LINE
}

\author{
Marie J. Myers \\ Faculty of Education, Queen's University (Canada)
}

\begin{abstract}
As teaching moved on-line we had to rethink and readjust what approaches to use in order to reach the outcomes. Adjustments had to be made to the designed activities especially when groups had to meet in breakout rooms.

We will present the various aspects that came under scrutiny, as for example, peripheral participation, the development of mini-communities of practice, cooperation, collaboration and mediation.

We analyzed instructor's journal notes and students' products. There were 53 students in the classes concerned.

The main research question is what was effective in making participants improve learning and how did the implementation increase their understanding of working together virtually.

The method used is qualitative (Creswell, \& Poth, 2018). The instructor took observational notes of processes and actions during planned activities. These notes were analyzed to uncover insights. In addition, student 'products' of group work were analyzed for the triangulation of results.

Results show that the effort put into creating more engagement in the module brought about a number of interesting results that increased student understanding. Overall, findings show that participants reiterate expectations and summarize them, the repetition allowed a better grasp and this could also be due to the fact that during the reconversion, participants had to make sure they really understood the contents, i.e. ensuring that the meanings were clear which, in turn led to a better intake of specific features. As regards working together, several issues were identified, yet overall, all students were highly successful, due mostly to a supportive approach as regards feedback or a 'feed-through' approach.

The theoretical underpinnings came from research on learning and pointed to the requirement of additional insights on the part of instructors especially when teaching has to take into account equity, diversity, inclusion and indigenization (EDII). Instruction had to be more connected to students' lives. Bransford et al (2000) assert that "to develop competence in an area of inquiry, students must: a) have a deep foundation of factual knowledge, b) understand facts and ideas in the context of a conceptual framework, and c) organize knowledge in ways that facilitate retrieval and application" (p. 16).
\end{abstract}

Keywords: Learning in the flipped classroom, examining success, issues and insights.

\section{General considerations}

Due to unprecedented circumstances we experienced the transposition from face to face to on-line teaching in the middle of a course. Thanks to new technological means, although learning situations might be very familiar, new parameters come into play. It is important to uncover their impact and what deviations might be caused (Myers, 2011; Sperber, \& Wilson, 1986). Many problems have surfaced over time in on-line teaching, and according to previous studies (Kebritchi, Lipschuetz, \& Santiague, 2017) these include overall, for teachers, issues around their changing roles, transitioning to on-line, time management and teaching style. As regards learners, problems stem from their expectations, their readiness, their identity and their participation. In terms of content, questions are related to course development, multimedia use, instructional strategies and the development of content. With the flipped classroom approach adopted, group work during in-class meetings was crucial to allow everyone's participation. When moving to on-line teaching while maintaining the same approach, a number of adjustments were necessary. We used zoom and placed student groups in breakout rooms. 
With breakout rooms students have to talk and show their competences in negotiating activities for completion by their group. This entails capacities around ways of being, in other words, behavior in social contexts. Processes however are not as clear cut as they may appear: it requires students to carry them out, to know what to do and to be willing to do it.

\section{The problem}

On-line dialogue is often reported as shallow or sparse. Indeed, meaningful dialogue can be elusive and discussion facilitation could produce more superficial dialogue.

The theoretical underpinnings came from research on learning and pointed to the requirement of additional insights on the part of instructors especially when teaching has to take into account equity, diversity, inclusion and indigenization (EDII) as in this case as mandated by the university. Instruction had to be more connected to students' lives.

As on-line teaching was mandated unexpectedly due to COVID the instructor had to find ways to cater to students and cover remaining course content in the middle of a semester. The course had been set-up using the flipped classroom approach which involved students mainly working in groups. Within this group work, while on-line, the instructor could only connect with breakout room participants, one breakout room at a time. Therefore, when the instructor is not present, the discussion taking place may not be very formal, nor would there be expectations as to what should be said next or saying what people want to hear which would happen when students know they are being observed (Myers, 2009). This could be positive as it allows students the freedom to 'intermingle virtually', of course as long as it is around the topic under scrutiny.

The instructor's presence while entering breakout rooms, places more pressure on group activity. By providing the group work, students are given an opportunity to use their new factual knowledge while having access to immediate feedback from peers and the instructor, and in that sense, the flipped classroom helps students learn to correct misconceptions and organize their new knowledge such that it is more accessible for future use. Furthermore, the immediate feedback that occurs in the flipped classroom also helps students recognize and think about their own growing understanding, thereby supporting Bransford and colleagues' major conclusion that "a 'metacognitive' approach to instruction can help students learn to take control of their own learning by defining learning goals and monitoring their progress in achieving them" (p. 18). As on-line teaching added new components to the instructor's teaching approach, everything done had to come under close scrutiny.

\section{Method}

\subsection{Approach}

Because of the nature of the study, a qualitative approach was best suited for researching details about categories and themes in the notes taken by the researcher during on-going class activity (Creswell $\&$ Poth, 2018). While reflecting upon what to improve for the following year, as on-line teaching was still mandated, the instructor analyzed journal notes she had taken all along to uncover what worked and what didn't in order to modify delivery for the following year. This study is based on observations in an academic context with 53 participants across different classes.

The context is a professional training program at a university for future teachers of French. Instructor's notes were analyzed to identify patterns and results were triangulated to uncover similarities and differences and students' assignments were also taken into consideration. Analyzing teaching notes and comments on assignments only involved notes on paper or looking at written assignments and there was no involvement of human subjects. For ethical considerations anonymity was maintained throughout. The decision to carry-out this analysis stemmed from a comparison of the instructor's notes from the first cohort of students, who had met face to face during the first half of the semester which was then followed up with on-line only contacts. This note taking is the regular practice of an instructor trying to improve course delivery.

The common basis for each group will be presented and overarching principles delineated showing how specific groups were affected. The evolvement of the learning contents was monitored and what had unfolded, contextualized. Possible underlying premises, perhaps untold, were uncovered during the analysis of the notes and are discussed.

As regards class procedures, the objective of the course was ensuring success, the best way to report on that was through the outcomes of work the students carried out. This work basically took two forms, one which consisted of on-going reinforcement discussions on content that had to be prepared ahead of class time and the second one, on actual assignments handed in. 
The theoretical framework for analyzing and interpreting the data came for both class participation and assignments from Bransford et al's (2000) assertion that "to develop competence in an area of inquiry, students must: a) have a deep foundation of factual knowledge, b) understand facts and ideas in the context of a conceptual framework, and c) organize knowledge in ways that facilitate retrieval and application" (p. 16).

\subsection{On-going interactions on topics to be assimilated}

Because of the nature of the study, a qualitative approach was best suited for researching details about categories and themes in the notes taken by the researcher during on-going class activity (Creswell \& Poth, 2018). While reflecting upon what to improve for the following year, as on-line teaching was still mandated, the instructor analyzed journal notes she had taken all along to uncover what worked and what didn't in order to modify delivery for the following year. This study is based on observations in an academic context with 53 participants across different classes.

The context is a professional training program at a university for future teachers of French. Instructor's notes were analyzed to identify patterns and results were triangulated to uncover similarities and differences and students' assignments were also taken into consideration. Analyzing teaching notes and comments on assignments only involved notes on paper or looking at written assignments and there was no involvement of human subjects. For ethical considerations anonymity was maintained throughout. The decision to carry-out this analysis stemmed from a comparison of the instructor's notes from the first cohort of students, who had met face to face during the first half of the semester which was then followed up with on-line only contacts. This note taking is the regular practice of an instructor trying to improve course delivery.

The common basis for each group will be presented and overarching principles delineated showing how specific groups were affected. The evolvement of the learning contents was monitored and what had unfolded, contextualized. Possible underlying premises, perhaps untold, were uncovered during the analysis of the notes and are discussed.

As regards class procedures, the objective of the course was ensuring success, the best way to report on that was through the outcomes of work the students carried out. This work basically took two forms, one which consisted of on-going reinforcement discussions on content that had to be prepared ahead of class time and the second one, on actual assignments handed in.

\subsection{Outcomes of assignments}

With the intent to promote success as the Ontario Ministry of Education' logo is success for all, and with an EDII policy we thrive at supporting every student. Therefore, we provide detailed guidance and continuous support to ensure successful completion, which is evidence of the learning that took place.

\section{Discussion}

Many studies of on-line teaching point to technical difficulties, lack of appropriate access to WIFI, poor connectivity, outdated equipment, we experienced none of these challenges. So we can start by stating that easy access to and quality of the technological means are necessary to ensure success. In this study we are looking more closely at the actual work students were expected to engage in.

In the instructor's journal notes she closely observed if a deep understanding of factual knowledge had taken place around each theme or topic, she took steps to check that students understood the conceptual frameworks underlying their professional practice and ensured activities and assignments were directly connected to the knowledge to be acquired. Success was measured by students' outcomes from both on-going class interactions on the weekly topics under scrutiny as well as the completion of their assignments during the semester.

On all fronts students did extremely well, although throughout there were some concerns that were addressed in order for students to improve upon their final work, evidence of the learning that took place. Themes uncovered were related to peripheral participation, the development of mini-communities of practice, cooperation, collaboration and mediation, both during interactions on topics covered and in-class discussions on assignments.

\subsection{Results from on-going interactions}

In class, questions were fielded and answered by peers as much as possible with follow-up by the instructor leading to further discussion and probing deeper into topics. Various degrees of interest in the new ideas were usually expressed. Through group interactions students were verifying factual foundations, thereby verifying their conceptual understanding. 
During the first semester of on-line teaching, compared to carrying out these processes in face-to-face teaching, it appeared that the whole class discussion during on-line teaching sparked more interest with more discovery. Indeed prior to on-line teaching, all peers in class could overhear what different groups discussed as well as interactions with the instructor. During on-line teaching after breakout rooms were left to gather the whole class together, there was some discovery of others' ideas that had not been heard before, altering some thinking, bringing about adjustments, more exchanges among groups with as well added challenges and variety in the interactions. More engagement from everyone was observed although some students early on only participated at the periphery which is legitimate too (Wenger, 1998; Lave \& Wenger, 1991). It appeared that some students were somewhat hesitant about using French, their second language and the language used in class. The further discrepancy was due to the fact that students have two teaching specialties and for some in these groups French was not their first choice. Nevertheless, over time they eased into using the language and were more active. These students sometimes used English to contribute to the discussion although when the instructor entered breakout rooms, French was usually being used, on occasion a sentence that had started out in English was continued in French. In view of this aspect, it could also be assumed that students who only spoke sporadically when the instructor had entered the room, might in fact have been actively engaged earlier on, although using the English language. Hence perhaps the problem was not at the level of lack of foundations in factual knowledge. Perhaps to have all students engage more fully, instead of groups of four or five in breakout rooms, some activities should be devised to have students work in pairs. This way upon the instructor's entry, it is possible to really observe both people interacting.

Given the requirement that materials be prepared ahead of class time, we would have anticipated that there would be an understanding of facts and ideas in the context of the presented conceptual frameworks, according to Bransford et al's thinking. Sometimes the instructor noticed a lack of depth in the students' preparation. This was further corroborated by the fact that some colleagues felt that they needed to administer a quiz at the beginning of each class. Although students seemed to demonstrate their understanding in their assignments, as is noted in the next section, sometimes a superficial discussion of important items led the instructor to doubting actual deep learning of some content. This being said we also have to note that often words cannot account for the big picture, so perhaps the thinking took place but the concepts had not materialized in their minds yet for retrieval verbally. There was also the suggestion by researchers to make the discussion questions harder in order to have students produce 'modified output' (Swain, 2000).

As regards the organization of knowledge to facilitate retrieval and application we uncovered the following. In the larger groups synergy among participants developed as they became mini communities of practice. During these in-class discussions of pre-studied materials, the atmosphere was usually relaxed among group members and because of the nature of the work to be completed as there were no wrong answers possible, they were commenting on their prior readings only bringing to light items of interest and proposing creative ideas to further enquiry into the field without set directions. Overall, findings show that at the start of each group meeting participants reiterated expectations and summarized them, setting up a workable format for themselves and clarifying understanding. Although they were not directed to do so, they clearly displayed excellent work habits and were interested in anchoring the knowledge gained. The repetition involved allowed a better grasp and this could also be due to the fact that during the reconversion, participants had to make sure they really understood the contents, i.e. ensuring that the meanings were clear which, in turn led to a better intake of specific features. During these discussions all aspects of the EDII policy could easily be accommodated.

Before on-line teaching the instructor could oversee the whole class and it was obvious that on-line the dynamics were different. It was especially concerning when dealing with more theoretical concepts. The instructor's presence, moving around the classroom kept everyone on their toes, actively engaged, even when discussions veered off, often students went on a tangent but still connected to the matters at hand, bringing in more personalized experiences to the table related to the topic. During on-line breakout room visits, as soon as the instructor joined, instructor's presence was acknowledged, either by greeting or through a pause, or redirecting a question at her. So although it was possible to glean a few seconds of the groups' activity, noticing whether they were on task or not, discussions were often quickly adjusted. Nevertheless, it was obvious that groups worked well together, in an efficient way and even when their talk was more of a socializing type it usually was related to the topics to be mastered, often through relating to some personal experiences and in this way also providing better ways for the crystallization of thought. Initially at least, it appeared that the students tried to figure out the instructor's positioning relative to the work assigned and also as a person which could somewhat explain this difference between the two semesters. 


\subsection{Results for assignments}

Models were given for all assignments so that students knew how to proceed although the idea never was to copy exactly the model given as models were only intended as guidelines with the idea to allow a wide margin of personal expression, as an EDII policy would be expecting to happen. Also to better support students, first assignments were group assignments in a cooperative way and then later in collaboration each student was to produce an original personal rendition with slightly different directions although working along similar lines as the group had been all together. So there was a progressive easing into the work to be submitted.

The assignments were given in order to develop students' competence in their area of specialty. Students were tasked with applications keeping in mind theoretical tenets that had been examined.

Findings point to overall supportive efforts although some restrain was sometimes observed even among people who were close. Students were advised that for these assignments they could meet outside class through their preferred application therefore minimizing the difficulty in using the technology. All students completed all their assignments at top level although some of them had to be given additional time, which was in line with university policy. For cooperative assignments, the groups came together well and produced superior work. For the following collaborative assignment students worked together, however each person had to hand in their own assignment after group collaboration.

\section{Conclusion}

During the instructor's breakout room entries, various degrees of reactions to inquisitiveness were noted, which could normally have been overlooked in face-to-face meetings (Rorty, 1991) as students would have known when the instructor was approaching their group. The use of silence and topic changes could be questioned at times, and some protectiveness of absentees was interesting. Some type of erosion or undermining was also identified, although of a different type, perhaps due to the different people involved (Scollon, \& Scollon, 1981). Whether the motives behind these interactions was just to redirect where an assignment was going, whether it was due to culturally different ways of being, it was noted that negotiations took place and after some mediating students got past the hurdles. Despite some perceived difficulties, it appears that there were negotiations of meaning and of content, the give and take in sharing ideas, and advice shared as how to better fulfill expectations listed in the assignment templates. So we can say that success, as per Bransford et al's (2000) quotes, has been identified at least in most of the areas concerned.

\section{References}

Bransford, J.D., Brown, A.L., \& Cocking, R.R. (2000). How people learn: Brain, mind, experience, and school. Washington, D.C.: National Academy Press.

Creswell, J., \& Poth, C. (2018). Qualitative inquiry and research design $\left(4^{\text {th }}\right.$ ed). ThousandOaks, Cal.: SAGE

Kebritchi, M., Lipschuetz, A.,\& Santiague, L. (2017). Issues and Challenges for Teaching Successful Online Courses in Higher Education: A literature review. Retrieved My 11, 2021 from https://doi.org/10.1177/0047239516661713

Lave, J., \& Wenger, E. (1991). Situated learning: legitimate peripheral participation. Cambridge, UK: Cambridge University Press.

Myers, M.J. (2011). Effectiveness in dialogic language use despite deviations. Procedia-Social and Behavioral Sciences 12, 248-254.

Osherson, D. (1995). The study of cognition. In L. Gleitman, \& M. Liberman (Eds.) Language. An invitation to cognitive science, vol. 1 . xi-xviii, Cambridge, Mass.: The MIT Press.

Rorty, R. (1991). Texts and lumps. In Objectivity and realism, Cambridge: Cambridge University Press 78-92.

Scollon, R., \& Scollon, S. (1981). Narrative, literacy and face in interethnic communication, Advances in Discourse Processes, vol 7. Norwood, N. J.: Ablex.

Sperber, D., \& Wilson, D. (1986). Relevance, communication and cognition. Oxford: Blackwell.

Swain, M. (2000). The Output Hypothesis and beyond: mediating acquisition through collaborative dialogue. In J.P. Lantolf (Ed.), Sociocultural theory and second language learning, 97-114. Oxford: Oxford University press.

Wenger, E. (1998). Communities of practice: learning, meaning, identity. Cambridge, UK: Cambridge University Press. 